\title{
PENGENALAN WARNA BERBASIS ANDROID MENGGUNAKAN METODE TEMPLATE MATCHING
}

\author{
Indra Hading Kurniawan ${ }^{1}$, Nurcahyani Dewi Retnowati ${ }^{2}$ \\ Departemen Informatika \\ Sekolah Tinggi Teknologi Adisutjipto Yogyakarta \\ Jl. Janti, Blok-R, Lanud Adisucipto Yogyakarta \\ Informatika@stta.ac.id
}

\begin{abstract}
Template matching method is a simple and widely used method to recognize patterns. The weakness of this algorithm is the limited model that will be used as a template as a comparison in the database such as shape, size, and orientation. The Extraction Feature algorithm addresses the problem of template models such as the shape, size, and orientation that exist in the matching template algorithm by mapping the characteristics of the image object to be recognized. Optical character recognition is used to translate characters into digital images into text formats. Its simple implementation makes the template matching method widely used. In this final project discusses the introduction of color in an image to be detected color, this color recognition is not fully successful because of the influence of lightness. The workings of this application take picture is by taking a picture and then the application identifies the color of any existing and will issue results in the form of text percent, with a success rate of $15 \%$ and $85 \%$ failure when detecting a color.
\end{abstract}

Keywords: Template Matching, Smartphone, Color, Picture

\section{Pendahuluan}

Perkembangan teknologi pada era saat ini memang tidak dapat dibendung lagi. Banyak aspek kehidupan yang mulai bergeser ke era teknologi informasi. Tidak dapat dipungkiri lagi kebutuhan akan kemudahan dan akses yang tak terbatas mulai dirasakan oleh kalangan masyarakat diseluruh dunia salah satu ilmu yang mendalami teknik pengolahan citra merupakan salah satu pencapaian besar umat manusia saat ini. Hal ini dibuktikan dengan mulai banyaknya device maupun software yang dapat mengenali banyak hal hanya dengan menggunakan sebuah gambar atau foto.

Pada penelitian ini proses pengenalan warna menggunakan teknologi yang sama pada penelitian sebelumnya tetapi metode yang digunakan berbeda yaitu metode yang digunakan template matching metode ini juga memiliki algoritma yang sama serta digunakan untuk mendeteksi bentuk sebuah objek meskipun hanya digunakan untuk itu pada tugas akhir ini metode tersebut dicoba untuk mendeteksi warna dari sebuah objek, metode template matching merupakan metode yang sederhana dan banyak digunakan untuk mengenali pola. Metode ini bekerja dengan cara mengevaluasi pola citra yang akan dibandingkan dengan pola citra template pada basis data. kelemahan metode ini adalah terbatasnya model yang akan dijadikan template sebagai pembanding pada basis data seperti bentuk, ukuran, dan orientasi. Oleh karena itu peneliti membangun media untuk pengenalan warna berbasis android dengan metode template matching.

\section{Tinjauan Pustaka}

Pemanfaatan Image To Speech Berbasis Android untuk Pengenalan Warna Bagi Anak Bawah Tiga Tahun (BATITA), peningkatan ini juga dipicu karena perkembangan perangkat lunak pada perangkat smartphone. Salah satu teknologi informasi yang banyak diguanakan dalam 
perangkat lunak komputer dan smartphone yaitu konversi bahasa tulisan menjadi bahasa percakapan dikenal sebagai text to speech [1].

\section{Landasan Teori}

\subsection{Template Matching}

Sebuah teknik dalam pengolahan citra digital untuk menemukan bagian-bagian kecil dari gambar yang cocok dengan template gambar. Template matching merupakan salah satu ide yang digunakan untuk menjelaskan bagaimana otak kita mengenali kembali bentuk-bentuk atau polapola. Template dalam konteks rekognisi pola menunjuk pada konstruk internal yang jika cocok (match) dengan stimulus penginderaan mengantar pada rekognisi suatu objek dengan template pada basis data. Template ditempatkan pada pusat bagian citra yang akan dibandingkan dan dihitung seberapa banyak titik yang paling sesuai dengan template.

Tingkat kesesuaian antara citra masukan dan citra template bisa dihitung berdasarkan nilai error terkecil dengan menggunakan persamaan

$$
\min e=\sum_{(x y) e w}(I x y-T x y)^{2}
$$

I adalah pola pixel citra masukan yang akan dibandingkan. $\mathrm{T}$ adalah pola pixel citra template. Template dengan nilai error paling kecil adalah template yang paling sesuai dengan citra masukan yang akan dibandingkan.

\subsection{Pengenalan dengan Algoritma Template Matching}

Pengenalan pola dengan menggunakan metode template matching dilakukan dengan cara membandingkan citra masukkan dengan citra template, citra masukkan dihitung berdasarkan gambar yang sesuai dengan citra template. Pixel citra biner ditelusuri mulai dari kiri atas hingga ke kanan bawah, citra biner dengan pixel berwarna hitam akan direpresentasikan dengan nilai 1 . Sedangkan pixel citra yang berwarna putih akan direpresentasikan dengan nilai 0. gambar yang mengilustrasikan angka 1 dan 0 yang mewakili nilai pixel citra [2].

\subsection{Proses Pencocokan Pola (Template Matching)}

Secara umum teknik pencocokan pola bertujuan untuk mengkalsifikasi dan mendeskripsi pola atau melalui pengukuran sifat-sifat atau ciri-ciri objek yang bersangkutan. Metode ini mendeteksi kehadiran suatu objek dengan mencocokkan citra yang untuk diketahui dengan sekumpulan citra lain yang menjadi acuan (template) metode dasarnya menggunakan logika ExOR; yaitu mengidentifikasi antara persamaan perbedaan suatu objek, misalnya, citra masukan tulang punggul sehat dibandingkan dengan citra template tulang panggul sehat maka tidak akan dihasilkan sebuah nilai yang menunjukkan tidak diketemukannya penyakit osteoporosis. Lain halnya jika citra masukkan tulang panggul sehat dibandingkan dengan citra template tulang punggul sakit maka akan dihasilkan sebuah nilai yang menunjukkan adanya penyakit osteoporosis [3].

\subsection{OpenCV}

OpenCV adalah sebuah library yang berisi fungsi-fungsi pemograman untuk teknologi computer vision secara real time. OpenCV sudah menggunakan antarmuka bahasa $\mathrm{C}++$ dan seluruh pengembangannya terdapat dalam format bahasa $\mathrm{C}++$. Contoh aplikasi dari OpenCV yaitu interaksi manusia dan computer, identifikasi, segmentasi dan pengenalan objek, pengenalan wajah, pengenalan gerakan dan penelusuran gerakan.

\section{Perancangan Sistem}

\subsection{Kebutuhan Perangkat Keras}

Satu unit laptop dengan spesifikasi :

1. Prosesor core i3 
2. $R A M 2 G B$

3. Harddisk $500 \mathrm{~GB}$

\subsection{Kebutuhan Perangkat Lunak}

1. Sistem Operasi Windows 10: Sistem Operasi digunakan untuk menjalankan main aplikasi, sehingga tanpa system operasi aplikasi tidak dapat dijalankan dengan sempurna

2. Android development tools, Eclipse, Opencv.

3. Objek: Citra digital bersumber dari smartphone android dengan format jpg dengan ukuran 400 x 300 piksel.

\section{3. $\quad$ Alur Proses}

Alur proses template matching dapat dilihat pada Gambar 1.

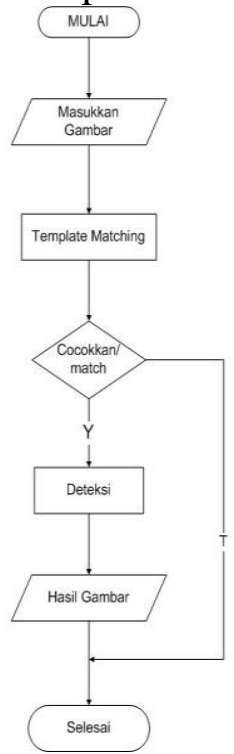

Gambar 1. Alur Proses Template Matching

\subsection{Use Case Diagram}

Use case diagram aplikasi dapat dilihat pada Gambar 2. Pengguna tidak dibatasi aksesnya terhadap aplikasi ini. Pengguna dapat menggunakan menu pengambilan citra baik dengan kamera maupun dari galeri. Kemudian pengguna dapat memproses citra tersebut dan aplikasi akan menampilkan hasil dari pengidentifikasian warna.

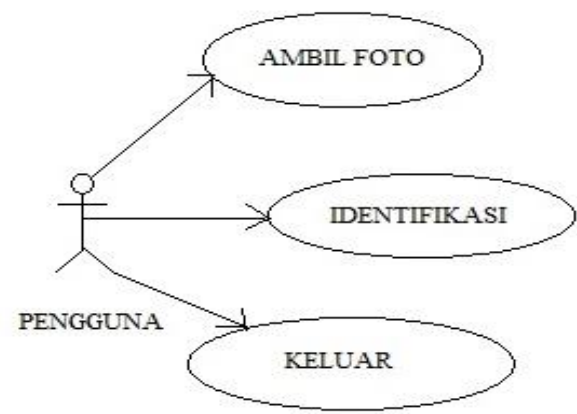

Gambar 2. Use Case Aplikasi

\section{Implementasi dan Pembahasan}

\subsection{Akusisi Citra}

Citra yang digunakan dalam pendeteksian warna merupakan citra yang bersumber dari smartphone android, baik foto secara langsung maupun dengan mengambil dari galeri. Sebelum 
citra diproses pada tahap selanjutnya terlebih dahulu citra diubah ukurannya menjadi $400 \times 300$ piksel guna mempercepat proses pendeteksian warna, lihat pada gambar 3 Sedangkan citra yang digunakan sebagai template warna merupakan citra dengan ukuran 30 x 30 piksel dan masingmasing citra mewakili 9 warna yaitu merah, kuning, hijau, biru, ungu, abu-abu, jingga, putih dan hitam (Gambar 4).

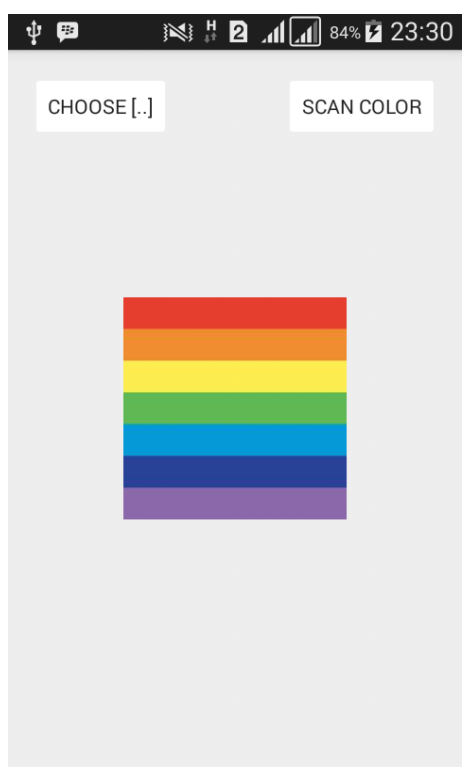

Gambar 3. Akuisisi Citra
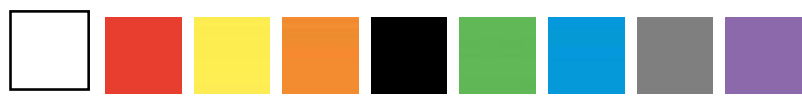

Gambar 4. Template 9 Warna

\subsection{Implementasi Template Matching Pada Smartphone Android}

Untuk mengimplementasikan metode template matching pada smartphone android terlebih dahulu memilih template dari warna dan dimasukkan kedalam resource yaitu pada folder res/drawable-hdpi dari aplikasi android agar nantinya penggunaan template ini menjadi lebih mudah dan mempercepat proses pengolahan (Gambar 5).

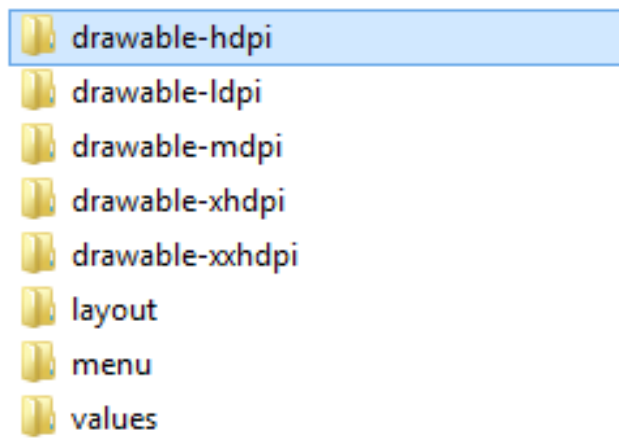

Gambar 5. Lokasi Penyimpanan Template Warna 


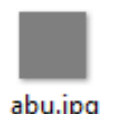

abu.jpg

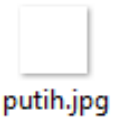

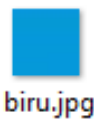

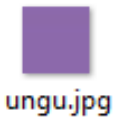

Gambar 6. Template Warna Pada Folder Drawable-Hdpi

Langkah selanjutnya buat file xml yang digunakan untuk membaca mengakses setiap template warna kedalam array (Gambar 7).

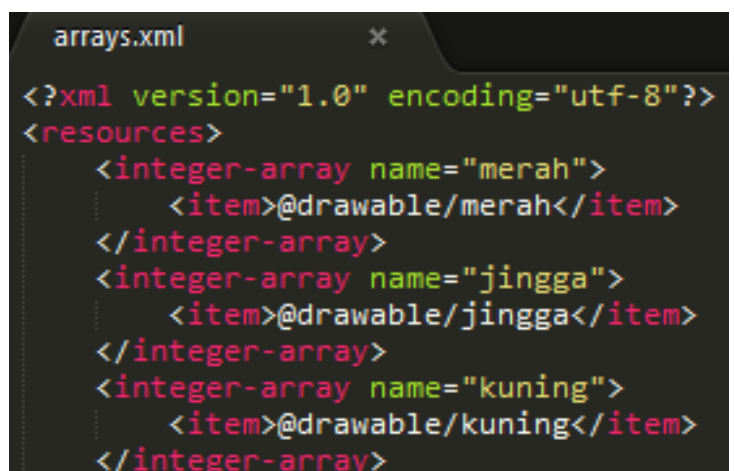

Gambar 7. File Xml Untuk Membaca Template Di Folder Drawable-Hdpi

Langkah selanjutnya aplikasi akan membaca setiap template dari folder drawabel-hdpi kemudian menggunakan metode template matching untuk mengidentifikasi setiap warna yang teridentifikasi pada citra yang sedang diproses.

Setelah keseluruhan template digunakan untuk mengidentifikasi warna pada citra, aplikasi akan membuat sebuah tanda pada citra yang teridentifikasi dengan tanda kotak/ rectangle pada bagian yang sesuai dengan template warna. Setelah proses identifikasi selesai maka dilakukan perhitungan kumulatif dimana seluruh warna yang terdeteksi dijumlah kemudian nilai pada setiap nilai dari template warna dihitung dengan persamaan $\frac{n}{t} \times 100 \%$ dimana $n=$ nilai dari setiap warna dan $t=$ nilai total dari warna yang terdeteksi. 


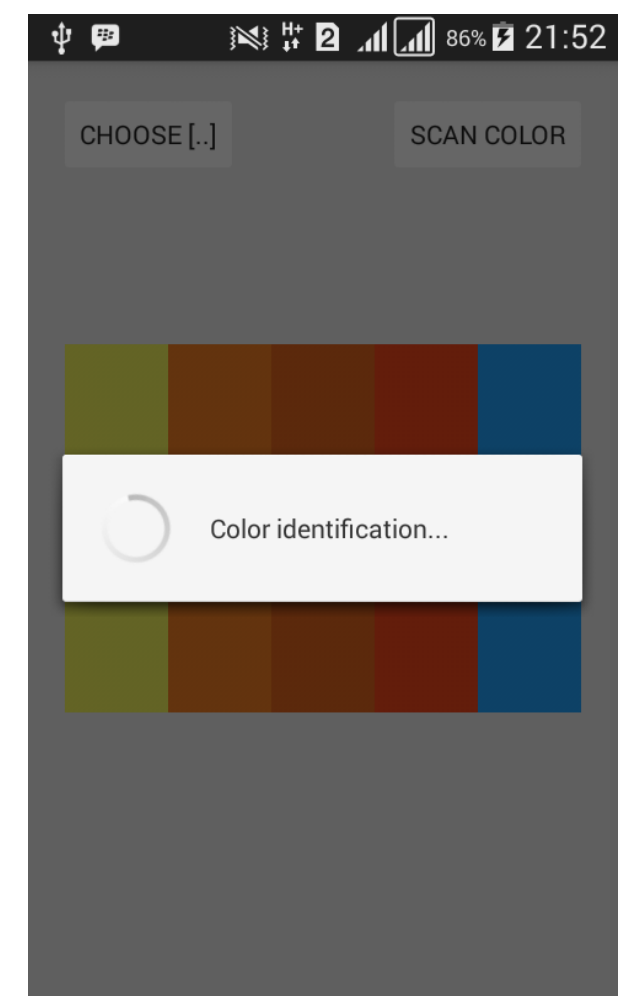

Gambar 8. Proses Identifikasi Warna

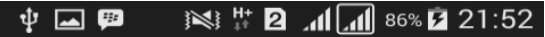

\begin{tabular}{l|l} 
CHOOSE [.] & SCAN COLOR
\end{tabular}

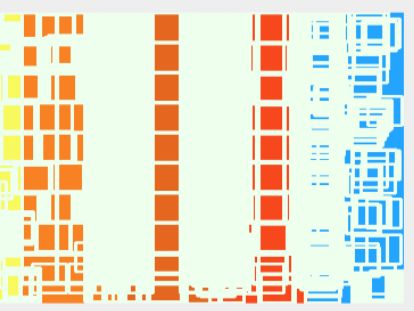

Gambar 9. Hasil Penandaan Bagian Warna Yang Teridentifikasi 


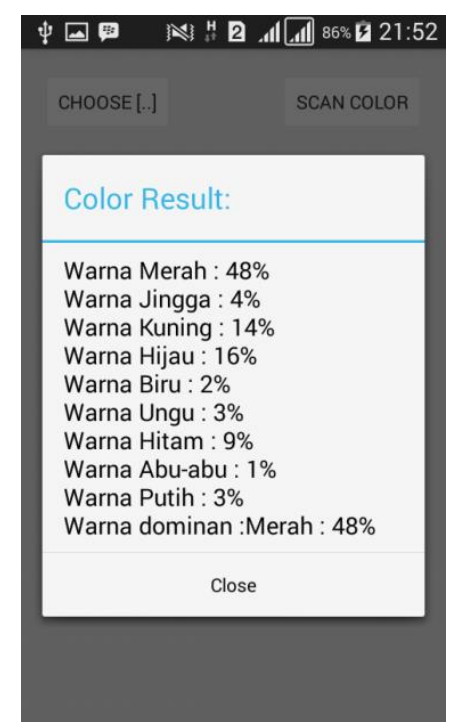

Gambar 10. Hasil Identifikasi Warna

Pada Gambar 8. merupakan proses identifikasi citra menggunakan template warna. Pada Gambar 9. merupakan hasil dari pengidentifikasian warna berupa citra yang telah ditandai sebagai bagian yang teridentifikasi sebagai warna dari setiap template. Pada Gambar 10. merupakan hasil dari perhitungan secara kumulatif dari total warna yang terdeteksi kemudian dilihat warna yang paling signifikan dari citra yang diproses. Sourcecode yang digunakan untuk proses template matching adalah sebagai berikut :

1. Imgproc.matchTemplate

2. Imgproc.rectangle

\subsection{Pengujian}

Pada pengujian ini dilakukan percobaan pengidentifikasian 40 citra yang memiliki warna dan karakteristik yang berbeda. Kemudian citra yang teridentifikasi dengan tepat akan dikategorikan dengan nilai 1 . Sedangkan pengidentifikasian yang tidak tepat akan dikategorikan dengan nilai 0 untuk melihat seberapa sering aplikasi dapat melakukan pemrosesan dengan hasil yang tepat maupun salah.

Dari hasil pengujian yang dilakukan pada ke-40 gambar berwarna diatas, didapat hasil keberhasilan pengidentifikasian warna sejumal 6 warna, sedangkan 34 warna yang lainnya terjadi kesalahan pengidentifikasian. Dari hal ini didapat keberhasilan pengidentifikasian yaitu $15 \%$ dan kegagalan sebesar $85 \%$ hasil yang didapat merupakan hasil uji coba yang telah dilakukan dengan histogram dan aplikasi template matching paparan perhitungan :

$$
\begin{aligned}
& \frac{6}{40} \times 100 \%=15 \% \text { Tingkat Keberhasilan identifikasi } \\
& \frac{34}{40} \times 100 \%=85 \% \quad \text { Tingkat Kegagalan identifikasi }
\end{aligned}
$$

\subsection{Pengaruh Jumlah Template Warna Terhadap Kecepatan Pemrosesan}

Akurasi dari pengidentifikasian sangat bergantung dari jumlah template dan karakteristik dari template yang beragam. Namun penambahan jumlah template warna akan mengakibatkan proses yang lebih lama dan akan menimbulkan kegagalan dalam proses pengidentifikasian. Hal ini dikarenakan aplikasi akan melakukan pemrosesan pada keseluruhan template terhadap citra yang diidentifikasi.

Penambahan jumlah template merupakan cara peningkatan akurasi pengidentifikasian warna. Hal ini dikarenakan metode template matching membutuhkan data yang bervariasi untuk meningkatkan akurasinya. Sehingga penambahan jumlah template bukan merupakan solusi yang tepat untuk meningkatkan akurasi pengidentifikasian warna. 


\section{Kesimpulan dan Saran}

\subsection{Kesimpulan}

Berdasarkan kegiatan yang telah dilaksanakan dalam penelitian ini, maka dapat diambil beberapa kesimpulan, diantaranya:

1. Metode template matching tidak dapat bekerja dengan maksimal jika digunakan untuk mengidentifikasi warna. Hal ini dilihat dari jumlah keberhasilan yang hanya mencapai $15 \%$ atas pengujian yang dilakukan pada 40 citra.

2. Implementasi metode template matching pada aplikasi android dapat dilakukan dengan menggunakan library opencv. Kecepatan pemrosesan bergantung pada jumlah template warna dan ukuran dari citra yang diproses.

\subsection{Saran}

Dalam penelitian mengenai pengidentifikasian warna ini tidak terlepas dari beberapan kekurangan. Oleh karena itu, penulis menyarankan beberapa hal, antara lain:

1. Penggunaan metode lain dalam mengidentifikasi warna agar pada penelitian selanjutnya dapat dilakukan dengan lebih akurat.

2. Penggunaan metode template matching pada pendeteksian citra akan lebih akurat jika menggunakan template yang memiliki karakteristik yang detail dan tidak hanya terpaku pada perbedaan warna saja. Tetapi juga semua ciri dari citra tersebut.

\section{Daftar Pustaka}

[1] Wintolo, Hero dkk., 2015. Pemanfaatan Image To Speech Berbasis Android Untuk Pengenalan Warna Bagi Anak Bawah Tiga Tahun (Batita). Jurnal Angkasa Volume 7 No.2 , November 2015, Sekolah Tinggi Teknologi adisutjipto ,Yogyakarta.

[2] Bahri, Raden Sofian dkk., 2012. Perbandingan Algoritma Template Matching Dan Feature Extraction Pada Optical Character Recognition. Jurusan Teknik Informatika, Universitas Komputer Indonesia, Bandung.

[3] Umam, Choirul., 2015. Deteksi Osteoporosis Dengan Metode Template Matching Pada Citra Sinar Rontgen Tulang Panggul Manusia. Jurusan Teknik Informatika, Universitas Dian Nuswantoro, Semarang

[4] Cahyana, Fajar MIT., 2014. Perancangan Program Penghitung Jumlah Kendaraan Di Lintasan Jalan Raya Satu Arah Menggunakan Bahasa Pemrograman C++ Dengan Pustaka Opencv. Universitas Brawijaya, Malang.

[5] Dennis, Alan dkk. 2005. System Analysis Design with UML version 2.0 an Object-Oriented Approach. Wiley. Indiana University. 